\author{
Classification \\ Physics Abstracts \\ $81.15 \mathrm{C}-68.55-72.15 \mathrm{E}$
}

\title{
Structure and properties of rf magnetron sputtered $W$ films
}

\author{
Marie-Christine Hugon $\left({ }^{1}\right)$, Chantal Arena $\left({ }^{3}\right)$, Bernard Agius $\left({ }^{1}\right)$, Michel Froment $\left({ }^{2}\right)$, \\ Françoise Varniere $\left({ }^{1}\right)$ and Colette Vignaud $\left({ }^{2}\right)$
}

( $\left.{ }^{1}\right)$ Institut Universitaire de Technologie de Paris Sud, Plateau du Moulon, BP 127, 91403 Orsay Cedex, France

$\left({ }^{2}\right)$ Physique des Liquides et Electrochimie, UPR5, CNRS, Université Pierre et Marie Curie, Tour 22, 4 Place Jussieu, 75230 Paris Cedex 05, France

$\left({ }^{3}\right)$ LETI/IRDI CENG, 85X, 38041 Grenoble Cedex, France

(Received April 24, 1990; accepted August 10, 1990)

Résumé. - Nous avons étudié les films de tungstène déposés sur support $\mathrm{SiO}_{2}$ par pulvérisation cathodique magnétron sous faible densité de puissance $\mathrm{rf}\left(1,7 \mathrm{~W} . \mathrm{cm}^{-2}\right)$. Des examens en diffraction électronique par réflexion, en diffraction de rayons $\mathrm{X}$ et en microscopie électronique à transmission corrélés à des mesures de résistivité et de contraintes, nous ont permis de montrer que : (i) les propriétés des films non polarisés, en particulier leur conduction électrique et la taille des grains, évoluent en fonction de la température instantanée de dépôt $\left(<150^{\circ} \mathrm{C}\right)$. Ces films sont essentiellement cristallins, de type $\beta$ et présentent comme prévu une forte résistivité ( $>1 \mu \Omega . \mathrm{m})$ et des contraintes en tension; (ii) sous faible polarisation, la structure $\beta$ évolue vers un mélange $\alpha+\beta$, sous l'influence du bombardement des ions argons, pour devenir $\alpha$ sous forte polarisation $(-150 \mathrm{~V})$. Les dépôts présentent alors une faible résistivité $(0.1 \mu \Omega . \mathrm{m})$ et des contraintes en compression élevées. Il semble que la température instantanée en cours de dépôt et la polarisation du substrat apparaissent comme les 2 paramètres fondamentaux contrôlant la microstructure, la résistivité et les contraintes des films de tungstène.

\begin{abstract}
In this work, the electrical and structural properties of tungsten, deposited with a magnetron cathodic sputtering system used in $\mathrm{rf}\left(13.56 \mathrm{MHz}-1.7 \mathrm{~W} . \mathrm{cm}^{-2}\right)$ on silicon wafer covered with undoped oxide are described. RHEED, X-ray diffraction and TEM were used to relate the microstructure to the resistivity and the stresses of the W films. Without bias voltage, the resistivity and the grain size are associated with the instantaneous substrate temperature $\left(<150^{\circ} \mathrm{C}\right)$. The films consist of a continuous $\beta$-W phase. High resistivity $(>1 \mu \Omega . \mathrm{m})$ and tensile stresses are measured. Under low negative bias voltage $(-50 \mathrm{~V})$, a mixture change of the $\alpha-\mathrm{W}$ phase to the $\beta$-W one is detected. At higher bias voltage $(-150 \mathrm{~V})$, the $\beta$ phase changes to $\alpha$ one. The atomic peening is responsible for the production of high compressive stresses and low resistivity $(0.1 \mu \Omega . \mathrm{m})$.
\end{abstract}




\section{Introduction.}

In recent years, refractory metals such as $\mathrm{W}$ or Mo have gained more and more importance in very large scale integrated (VLSI) circuits. Since the feature size scale is below $1 \mu \mathrm{m}$, device delays become small compared to interconnection ones. To obtain faster switching, the metallization of interconnects plays a major role. The $\mathrm{W}$ presents many advantages. It has a low electrical resistivity both in bulk $(\rho=0.056 \mu \Omega . \mathrm{m})$ and thin film form, it is a good diffusion barrier and its refractory nature allows postdeposition processing at high temperature. It offers a high resistance to electromigration and a fine patternability with fluorine gases. These attractive properties are also used for Si ohmic contacts and for MESFET (Metal semiconductor field effect transistor) gates or HBT (Heterojunction bipolar transistor) emitter contacts in III-V technology. The two methods most widely used for W deposition are CVD (Chemical vapor deposition) and sputtering. CVD has become the deposition method of choice over sputtering. In general CVD films exhibit better step coverage compared to sputtered ones. However these films have very high stresses and a poor adhesion on dielcctric surfaces $\left(\mathrm{SiO}_{2}\right.$ and $\left.\mathrm{Si}_{3} \mathrm{~N}_{4}\right)$. So , they require a "glue layer" such as sputtered W to improve this characteristic. The advantage of using sputtered W is related to its stress which can be very low by adjustment of deposition parameters. The aim of this present paper is to study sputtered $\mathrm{W}$ on $\mathrm{SiO}_{2}$ and to correlate its microstructure with its electrical resistivity and its residual stresses. In the literature, few data are available concerning the structure of rf magnetron sputtered W films, determined thanks to transmission electron microscopy observations $[1,2]$.

\section{Experimental.}

The experimental procedure has been extensively described in references [3] and [4]. Each silicon wafer, covered with $500 \mathrm{~nm}$ oxide is tested by Newton ring interferometry to verify that the wafer exhibits a small number of interference fringes. Only the substrates with a low initial curvature (substrate deflection $<5 \mu \mathrm{m}$ ) are used. All W films are deposited in a rf magnetron sputtering provided by ALCATEL compagny at low Ar pressure ( $0.5 \mathrm{~Pa})$ on 4 inch silicon oxide in dynamic mode. The films are obtained using $1.7 \mathrm{~W} . \mathrm{cm}^{-2}$ power density and several substrate biases $(0,-50 \mathrm{~V},-150 \mathrm{~V})$. This low power density is used because it induces low stresses in the deposited films [3]. The stresses are calculated from the change in deflection curvature of the silicon wafer before and after deposition. Electrical resistivity is measured with a conventionnal four-point probe. Film thicknesses, ranging from 20 to $500 \mathrm{~nm}$, are measured by Rutherford backscattering spectrometry (RBS). Nuclear reaction analysis (NRA) is used to obtain oxygen content in the film. In order to characterize the microstructure of the films, reflection high energy electron diffraction (RHEED), X-ray diffraction and scanning electron microscopy (SEM) are performed. To get a better understanding, some layers are also examined by transmission electron microscopy (TEM). The thin samples were prepared by ion milling and observed in a JEOL 2000 FX transmission electron microscope operating at $200 \mathrm{kV}$.

\section{Results and discussion.}

3.1 RESISTIVITY. - The variation of the electrical resistivity as a function of the thickness and for three different bias voltages is shown in figure 1 . Varying from $2 \mu \Omega$.m to $0.1 \mu \Omega$.m,the resistivity appears to be dominated by the bias voltage and by the substrate temperature correlated to the film thickness (Fig. 1). Generally, such variation is explained by impurity inclusions, which 
could be oxygen or argon in our case, or by the grain size of the film. RBS analysis has been used for the determination of heavy atoms in the films deposited on $\mathrm{SiO}_{2}-\mathrm{Si}$ structure and shows that they are free of any contaminant heavier than silicon. In particular, this measurement demonstrates that the Ar content is less than $10^{+13}$ at. $\mathrm{cm}^{-2}$ - the detection limit in our RBS measurements. So the resistivity evolution is not due to argon inclusion. Concerning the oxygen, we have to consider two behaviors. First of all, for a same bias voltage, as the oxygen contamination decreases from 4 at $\%$ to 0.3 at \% [4], the resistivity evolution can be related to this decrease i.e. to the oxygen sticking probability (insert of Fig. 1) which is less important when the instantaneous surface temperature is higher. On the other hand, no oxygen variation is observed for different polarisation values. However, the film resistivity is substantially improved when the bias voltage increases : $-150 \mathrm{~V}$ induces the lowest value $(0.1 \mu \Omega . \mathrm{m}$ for thickness $>300 \mathrm{~nm})$. So, the resistivity decrease cannot be correlated to impurities in the films. This behavior is then attributed to the microstructure. The resistivity measured in the present study appears to be higher than the bulk value $(0.056 \mu \Omega . \mathrm{m})$. But it is enough for its different applications in microelectronics.

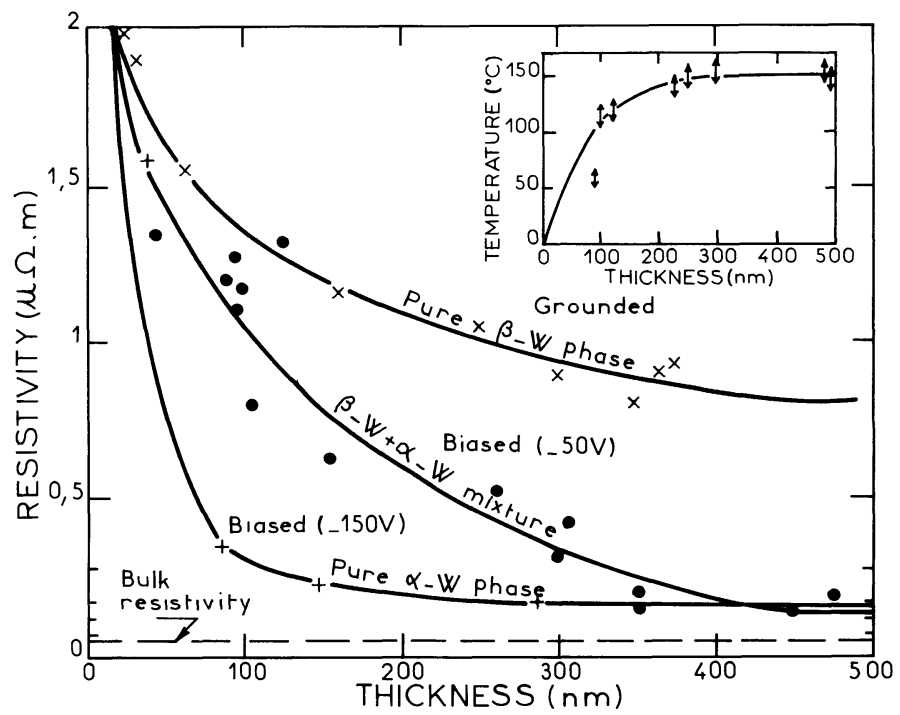

Fig. 1. - Room temperature resistivity as a function of film thickness, for three different bias voltages. In insert, temperature as a function of film thickness ( $\mathrm{rf}$ power density : $1.7 \mathrm{~W} . \mathrm{cm}^{-2}$, argon pressure: $0.5 \mathrm{~Pa}$ ).

3.2 Film STRESSES. - The dependence of the film stresses as a function of the W thickness is shown in figure 2 for various bias voltages. The film stresses can vary extensively by changing bias voltage from tensile values $(0 \mathrm{~V})$ to compressive ones $(-150 \mathrm{~V})$ under a same substrate temperature. Therefore the large stress variations are mainly due to intrinsic stresses rather than thermal ones. These results and those related to oxygen contamination imply that other factors such as microstructure $(\beta-\mathrm{W}$ or $\alpha-\mathrm{W})$, grain size, microvoids must dominate stress characteristics. The evolution of the stress nature as a function of the polarisation voltage shows that there is a value of the bias voltage which allows to get a W film without stress. But the choice of this value must be made with regard to other properties such as resistivity and microstructure. 


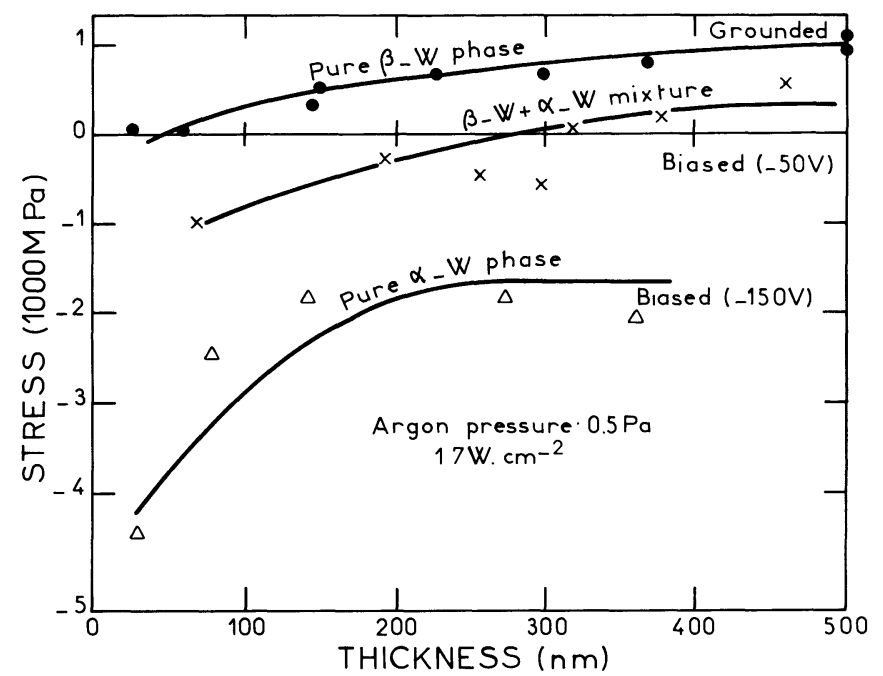

Fig. 2. - Stress as a function of film thickness for three bias voltages ( $\mathrm{rf}$ power density : $1.7 \mathrm{~W} . \mathrm{cm}^{-2}$, argon pressure : $0.5 \mathrm{~Pa}$ ).

\subsection{Microstructure.}

3.3.1 Films without bias voltage. - The microstructure of the deposited films without bias voltage was examinated by RHEED [3] . The electron diffraction diagrams (Fig. 3) show that only $\beta$-W phase $(a=0.504 \mathrm{~nm})$ is present in the films in the range of the thicknesses studied here $(50-500 \mathrm{~nm})$. Since the $\mathrm{W}$ films have a higher density than that of bulk, the $\beta$-W phase is metallic. This phase has a $\mathrm{A} 15$ crystal structure corresponding to either $\mathrm{W}_{3} \mathrm{~W}$ tungsten or $\mathrm{WO}_{3}$. The presence of $\mathrm{WO}_{3}$ has never been dectected by RHEED, however a very small amount can be observed by X-ray diffraction. This result is correlated to a low oxygen content in the deposited layers varying from 4 at $\%$ to 0.8 at $\%$. This oxygen evolution allows us to conclude, contrary to other discussion [5], that the $\beta$-phase is not stabilized by amounts of this element. A fiber texture with [100] crystallographic axis is always detected (Fig. 3). The perfection of this texture is improved with the thickness and therefore the substrate temperature (Fig. 1). To confirm and to complete the RHEED informations, some X-ray measurements were performed [3]. We have shown that the intensity of the (210) and (211) reflections remains the same whereas the intensity of the (200) reflection increases with time deposition [3] . These different results confirm the existence of a [100] preferential texture which is observed by RHEED and which is well defined for the highest thickness. The relative importance of this texture which increases continuously with thickness, indicates that the structural development is primarily dominated by growth process rather than by nucleation. The [100] texture shows a tendency to saturate for thicker films [3]. The improvement of the [100] texture with film thickness is correlated to the increase in mean grain size which can be estimated by X-ray broadening peak from 13 $\mathrm{nm}$ to $50 \mathrm{~nm}$. The mean grain size depends on the $\mathrm{W}$ thickness $(50-500 \mathrm{~nm})$ and therefore instantaneous temperature $\left(60-150{ }^{\circ} \mathrm{C}\right)$. At low temperatures, the $\mathrm{W}$ mobility is negligible and small grains are formed. For high temperatures, the atom diffusion on the substrate surface is easier and it leads to the formation of larger crystallites. However, the grain growth is limited by the relatively low deposition temperature $\left(<150^{\circ} \mathrm{C}\right)$ compared with the melting point of $\mathrm{W}$ $\left(3410^{\circ} \mathrm{C}\right)$. The electrical resistivity of unbiased films is directly controlled by the grain dimen- 
sions. The sharp resistivity decrease is probably due to the grain size increase. Nevertheless, this decrease (from $2 \mu \Omega$.m to $1 \mu \Omega . \mathrm{m}$ ) is limited by the presence of $\beta$-W. The cross section SEM micrographs in figure 4 reveal a columnar structure whatever the thickness. No microvoids are observed and this result is confirmed by TEM observations. So, the measured tensile stresses are not due to a porous structure. The $\beta$-W phase seems to induce tensile stresses and the improvement of the fiber texture perfection increases their level.

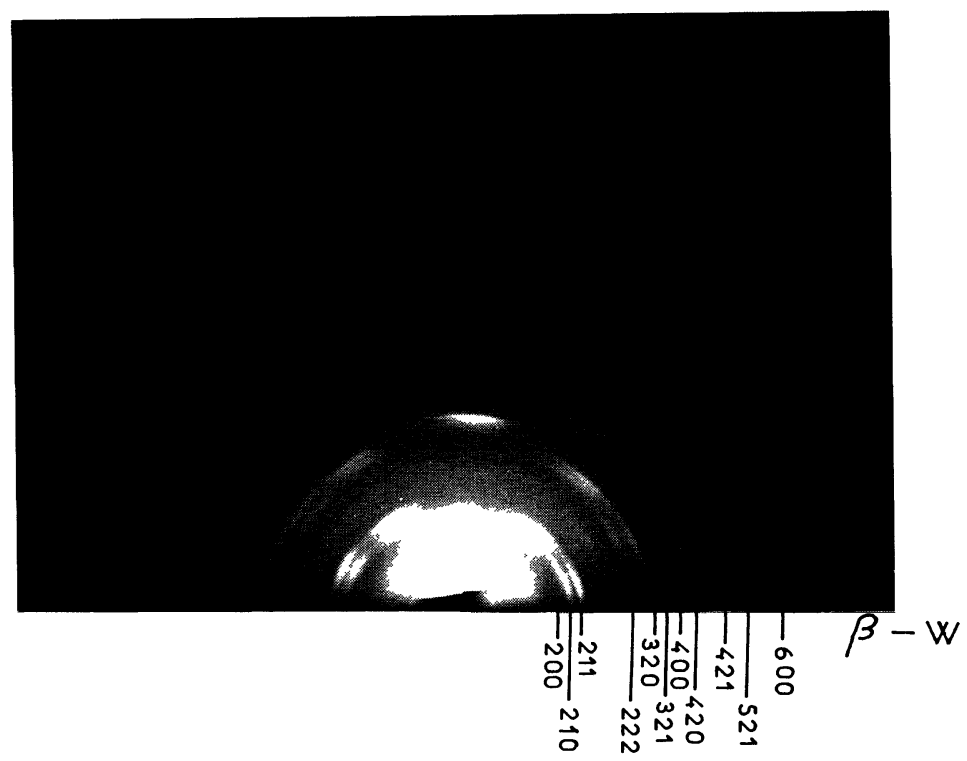

Fig. 3. - RHEED diagram obtained with a $\mathrm{W}$ film deposited under $0 \mathrm{~V}$ bias voltage ( $\mathrm{rf}$ power density : 1.7 W. $\mathrm{cm}^{-2}$, argon pressure: $0.5 \mathrm{~Pa}$, thickness: $570 \mathrm{~nm}$ ).

3.3.2 Films with bias voltage. - The pure $\beta$-W films have a too high resistivity. So, to minimize this parameter, we have applied a negative bias $(-50 \mathrm{~V},-150 \mathrm{~V})$ to the substrate (Fig. 1). The microstructure for the films deposited under $-50 \mathrm{~V}$ consists of a mixture of the $\alpha$-W phase and the $\beta$-W one : RHEED observations detect the $\beta$-phase at low thickness which changes to $\alpha$ phase at higher thicknesses (Fig. 5). X-ray which explores all the deposit, reveals the existence of the two phases. On the X-ray diffraction patterns, the peak intensity corresponding to the (110) reflection tends to increase with instantaneous temperature (Fig. $6 \mathrm{~b}$ ) whereas the $\beta$ peak corresponding to the (200) reflection decreases (Fig. 6a). The same behavior is observed for the two other $\beta$ reflections : (210) and (211). $-50 \mathrm{~V}$ value seems to induce the $\alpha$-W formation and to reduce the presence of $\beta$-W phase especially for high thicknesses $(>300 \mathrm{~nm})$. In the literature, the transformation of $\beta-\mathrm{W}$ into $\alpha-\mathrm{W}$ is referred to be possible around $140^{\circ} \mathrm{C}$. The instantaneous temperature during the process has almost the same value (Fig. 1). It seems that the bias voltage helps to reach faster this transition. The substrate polarisation is responsible for another effect : it improves the grain growth especially for low thicknesses. The grain size is estimated to be around $45 \mathrm{~nm}$ for all deposition times.

$-150 \mathrm{~V}$ bias value causes an important $\beta$-W phase reduction leaving only $\alpha$ phase (Fig. 6). A high voltage seems to stabilize $\alpha$-W. The sputter etching process creates surface defects acting as 


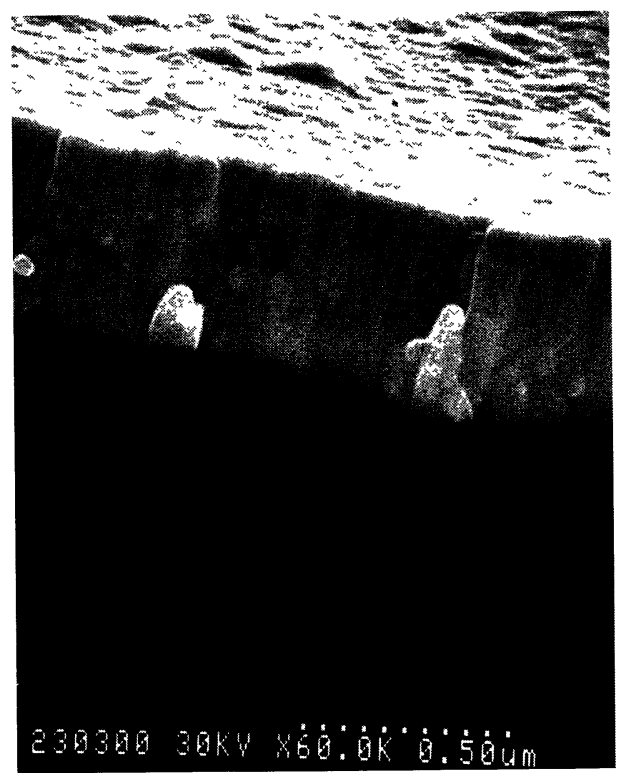

a)

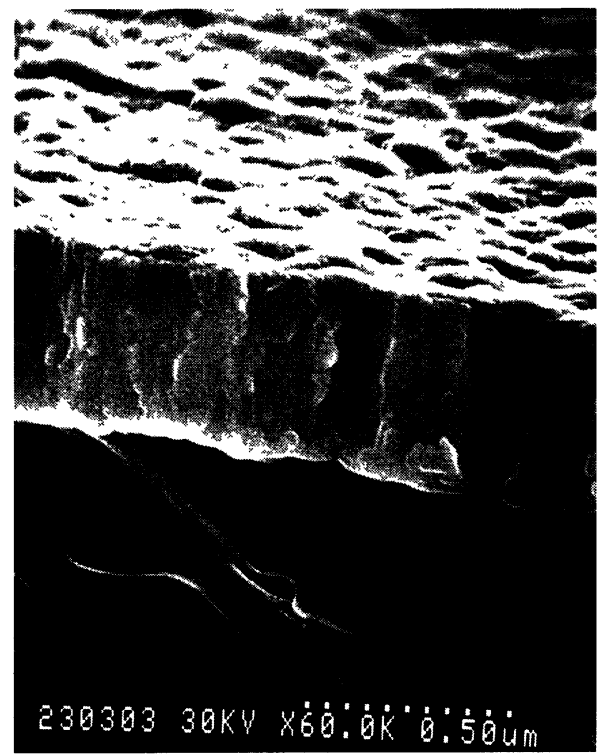

b)

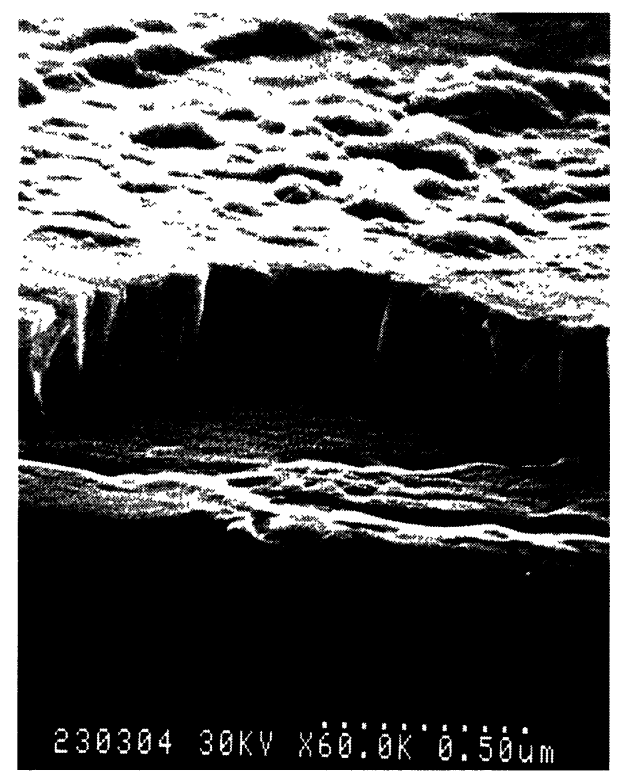

c)

Fig. 4. - SEM photograph of a cross section showing a $\mathrm{W}$ film deposited under different bias voltages (rf power density : $1.7 \mathrm{~W} . \mathrm{cm}^{-2}$, argon pressure : $0.5 \mathrm{~Pa}$ ). a) $0 \mathrm{~V} . \mathrm{b}$ ) $\left.-50 \mathrm{~V} . \mathrm{c}\right)-150 \mathrm{~V}$.

nucleation sites for arriving atoms and erodes the film retarding the grain growth. So, the films deposited under high bias values are made of fine grains and a [110] preferential orientation is observed. 
Although, the microstructure is altered by the polarisation, the cross section SEM micrographs of $\mathrm{W}$ films show that all films have a columnar structure and the same density $\left(19.7\right.$ g. $\mathrm{cm}^{-3}$ ) whatever the thickness and the bias voltage (Fig. 4). This density corresponds to the W bulk value contrary to other work [6] where smaller values $\left(15.8 \mathrm{~g} . \mathrm{cm}^{-2}\right)$ were found for e-beam deposited W. In spite of the energetic particle presence which sputters the films during its growth, no microvoids are observed. The anatomic peening process does not also affect the surface topography of $\mathrm{W}$ layers which is relatively smooth.

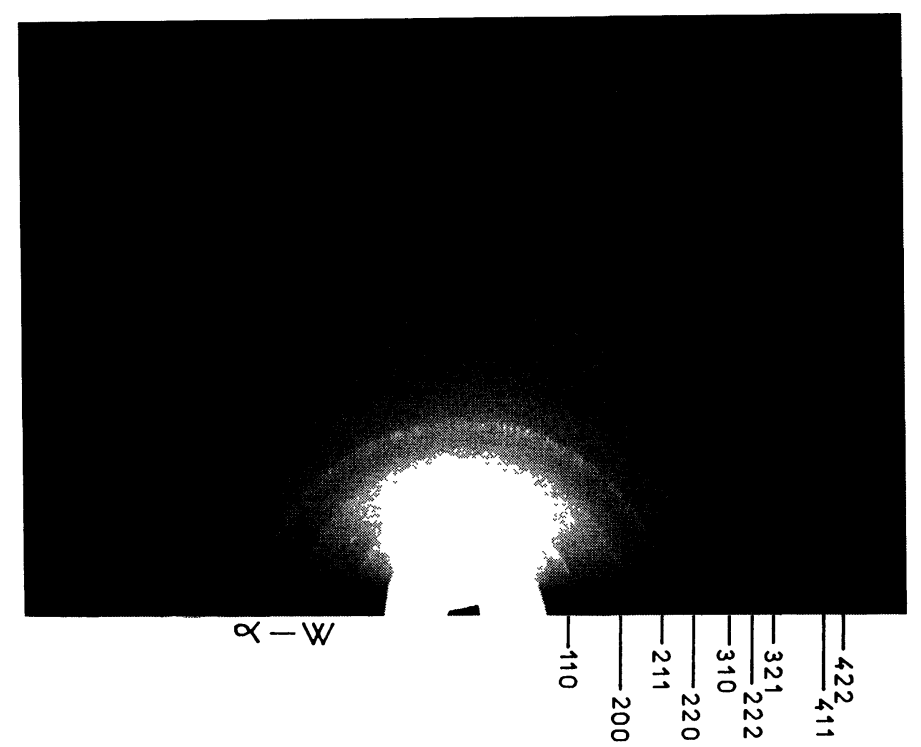

Fig. 5. - RHEED diagram obtained with a $\mathrm{W}$ film deposited with $-50 \mathrm{~V}$ bias voltage (rf power density: $1.7 \mathrm{~W} . \mathrm{cm}^{-2}$, argon pressure: $0.5 \mathrm{~Pa}$, thickness: $470 \mathrm{~nm}$ ).

3.3.3 TEM observations. - TEM observations of cross sections allow to visualize the textured growth of the tungsten films. Figures 7 illustrate the columnar growth of tungsten films deposited respectively with $0 \mathrm{~V},-50 \mathrm{~V}$ and $-150 \mathrm{~V}$ bias voltages. The individual columns present different contrasts which permit to determine their diameter which is found in the 10-20 nm range, in good agreement with X-ray diffraction estimations. Inside the columns, HREM observations have been performed. A striking feature of the tungsten layers is the considerable number of areas where moire fringes are observed. These moirés fringes are due to the interference effects between two overlapping tungsten crystals of different orientations. For example figure 8 shows moiré fringes spacings of $0.455 \mathrm{~nm}$ which could be due to the overlapping of (210) and (222) oriented tungsten grains. Inside the columns lattice fringes can also be frequently observed. Figures 9 and 10 show lattice images spaced at $0.252 \mathrm{~nm}, 0.225 \mathrm{~nm}, 0.206 \mathrm{~nm}$ which correspond, within experimental error, respectively to the (200), (210) and (211) interreticular distances. These lattice fringes run in domains the size of which is generally more than $15 \mathrm{~nm}$. Lattice fringes corresponding to the (200) interreticular distance are most frequently observed. This observation is in agreement whith the (200) texture which has been detected by RHEED and X-ray diffraction. Figure 11 shows an arrangement of perpendicular fringes regularly spaced at $0.504 \mathrm{~nm}$. This image could be inter- 


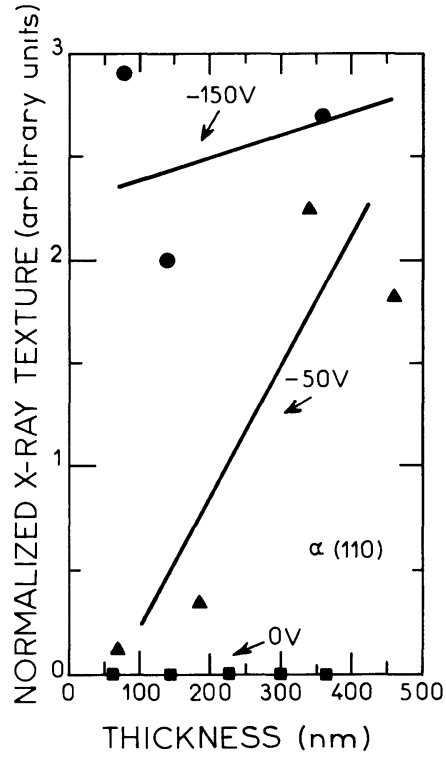

a)

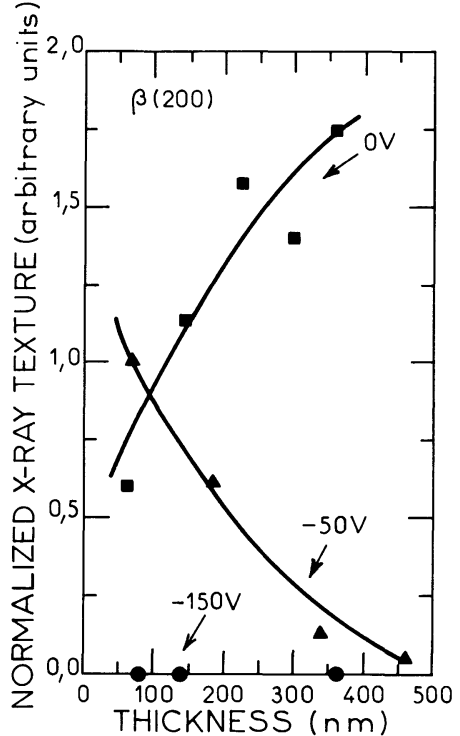

b)

Fig. 6. - Normalized X-ray texture as a function of film thickness for different bias voltages: a) $\beta$ peak corresponding to $\left\langle 200>\right.$; b) $\alpha$ peak corresponding to $<110>$. (rf power density: $1.7 \mathrm{~W} . \mathrm{cm}^{-2}$, argon pressure: $0.5 \mathrm{~Pa})$.

preted by the formation of moiré fringes from interferences between $\mathrm{W}$ domains presenting the (211) and (222) orientations. The $0.504 \mathrm{~nm}$ distance corresponds also to the (100) interreticular distance. As a matter of fact this reflexion is not allowed in the $\beta$-tungsten. Nevertheless, dynamical effects could increase the contribution of the (100) beam which would become predominant. The tungsten films formed with a $-150 \mathrm{~V}$ bias voltage show the most important density of domains where lattice or moiré fringes are observed. This result can be connected to the low resistivity and the high compressive stresses of these tungsten films. All microdiffraction diagrams coming from cross section or from samples thinned on the plane of the films correspond according to the bias voltage, to $\beta, \alpha-\mathrm{W}$ or mixture of the two phases (Fig. 12). Any other intense reflection cannot be detected confirming the absence of compounds in the tungsten films.

3.4 DisCuSSION. - The crystalline structure and phase are strongly influenced by bias voltage which affects properties such as stresses and resistivity. We can note a large decrease in the resistivity for the samples under bias. The resistivity of the polarised films is one order of magnitude lower. To obtain the minimum value $(0.10 \mu \Omega . \mathrm{m})$, a voltage of $-150 \mathrm{~V}$ must be applied. The use of negative bias generally helps to resputter impurity atoms from growing films and a low resistivity can be obtained. It is not the case for this study. This parameter has no influence on oxygen and argon contamination. The low resistivity is only due to the presence of pure $\alpha-\mathrm{W}$ film. In all conditions, the $\mathrm{W}$ films have been found dense and contrary to the case of CDV films no pores have been observed.

Negative bias is a major source of compressive stress formation. The minimum resistivity deposition condition $(-150 \mathrm{~V}$ bias voltage) for $\mathrm{W}$ films induces high compressive stresses and is not compatible with minimum stress (around $-50 \mathrm{~V}$ ). However there are no observations of peeling 


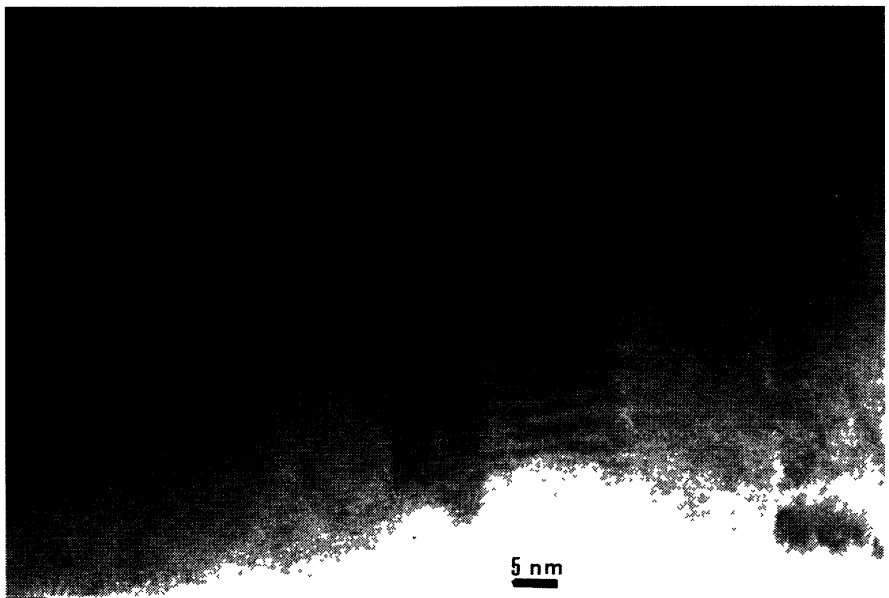

a)

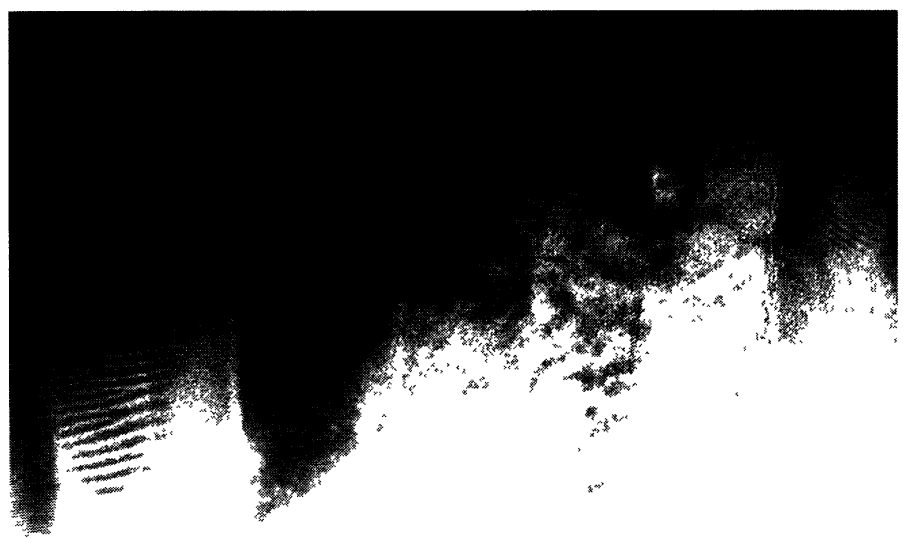

$5 \mathrm{~nm}$

b)

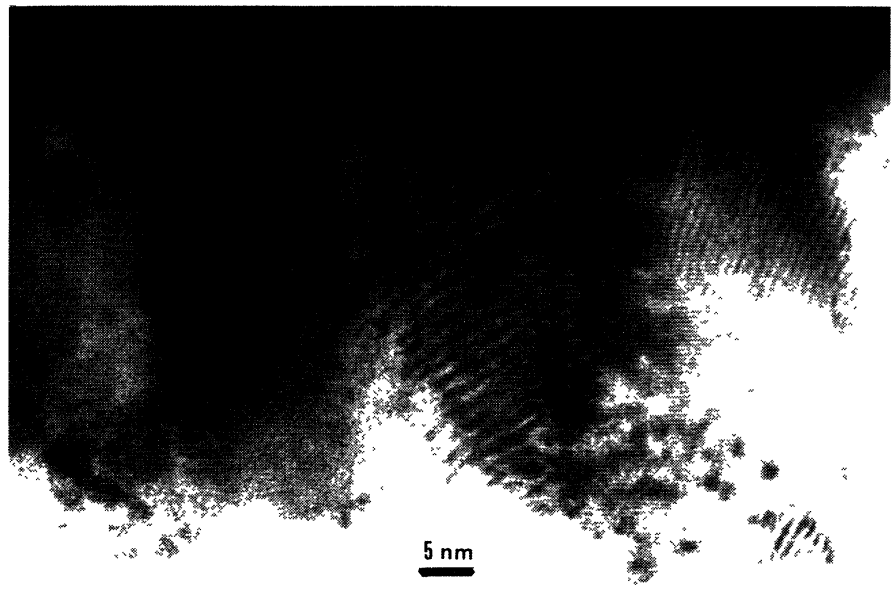

c)

Fig. 7. - TEM observation of $\mathrm{W}$ cross section: a) bias voltage $0 \mathrm{~V}, \mathrm{~b}$ ) bias voltage $-50 \mathrm{~V}$, c) bias voltage $-150 \mathrm{~V}$. 


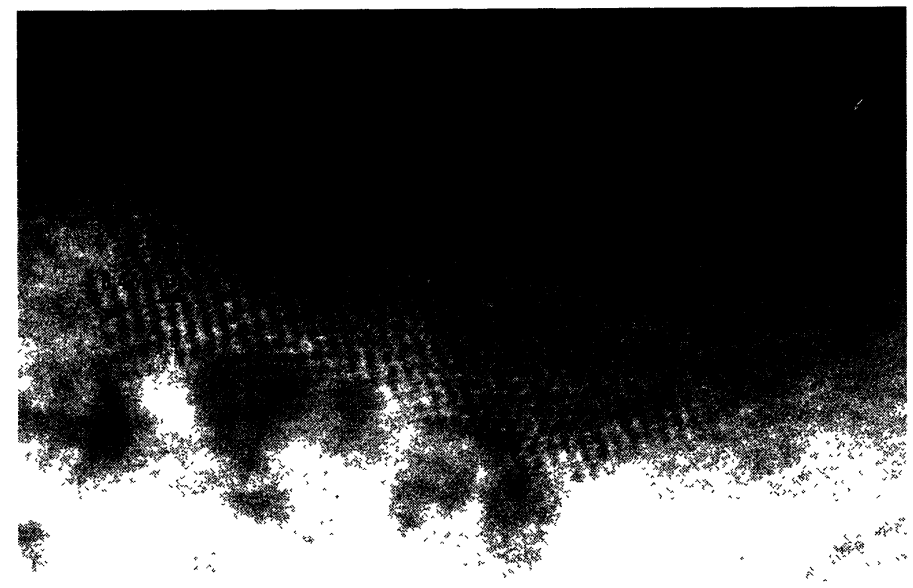

Fig. 8. - Tungsten film deposited with $0 \mathrm{~V}$ bias voltage. Moiré fringes (spacing $0.455 \mathrm{~nm}$ ) are superposed with lattice fringes corresponding to the (210) and (222) interreticular distances.

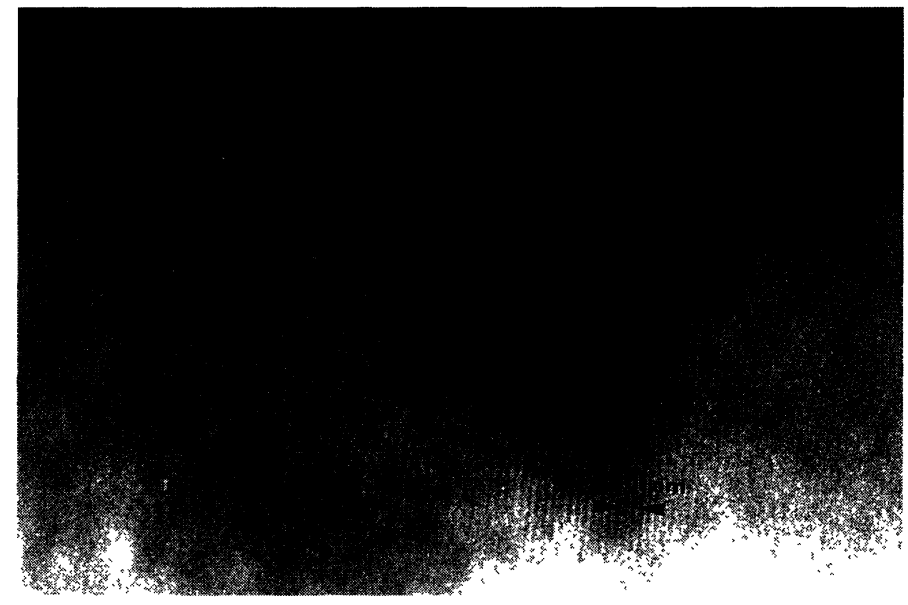

Fig. 9. - Tungsten deposited with $-50 \mathrm{~V}$ bias voltage. Lattice fringes corresponding to the (210) interreticular distance.

or cracking. For a given thickness, the stress can vary from tensile to compressive as a function of the bias voltage. This evolution is correlated to $\beta$-W $\rightarrow \alpha$-W phase transformation and strongly marked columnar growth. It evidently passes through the zero value which corresponds to a particular $\beta-\mathrm{W} / \alpha-\mathrm{W}$ presence ratio. Three mechanisms can explain the development of compressive stresses: impurity incorporation (oxygen), sputter gas entrapment (argon) and atomic peening. Since the films $(>200 \mathrm{~nm})$ are oxygen free $(<1$ at $\%)$ and argon has never been detected, the third mechanism is responsible for the production of compressive stresses. It is possible that 


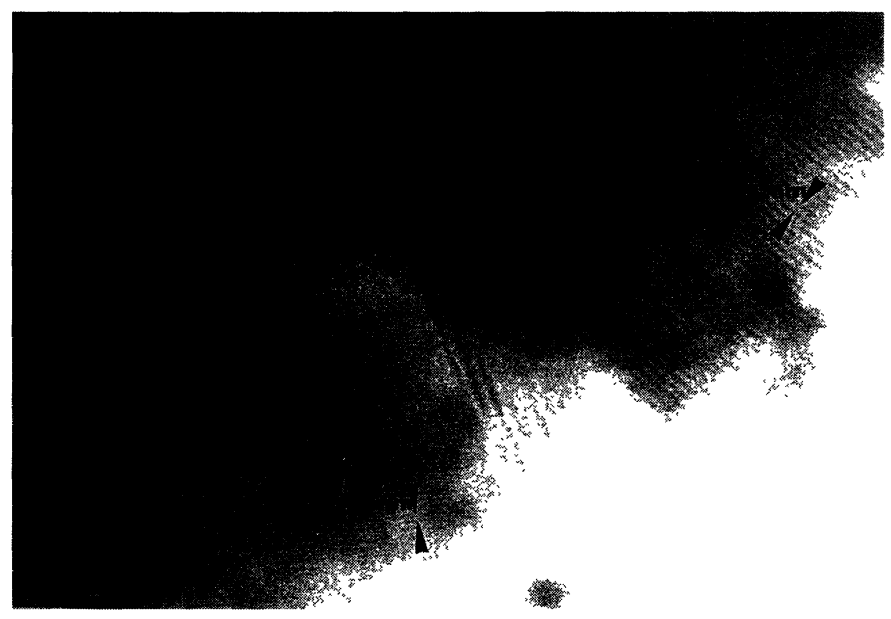

Fig. 10. - Tungsten deposited with $0 \mathrm{~V}$ bias voltage. Lattice fringes corresponding to the (200) and (211) interreticular distances.

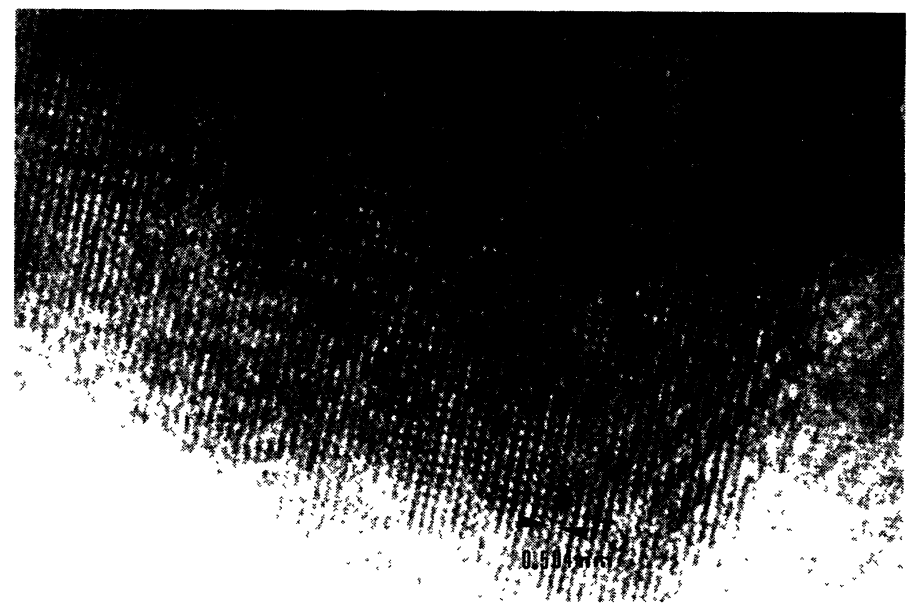

Fig. 11. - Tungsten deposited with $-150 \mathrm{~V}$ bias voltage. Regular array of fringes separated by $0.504 \mathrm{~nm}$.

the energetic particles striking the growing film induce a lattice distortion and therefore stresses. Careful comparison of data obtained by resistivity measurements, interferometry, X-ray diffraction and RHEED reveal the importance of the microstructure of the films directly correlated to the substrate temperature. The microstructure of films is established through nucleation, thickness and structural relaxation which occur during the deposition process. The nucleation has a small influence compared with grain growth. 


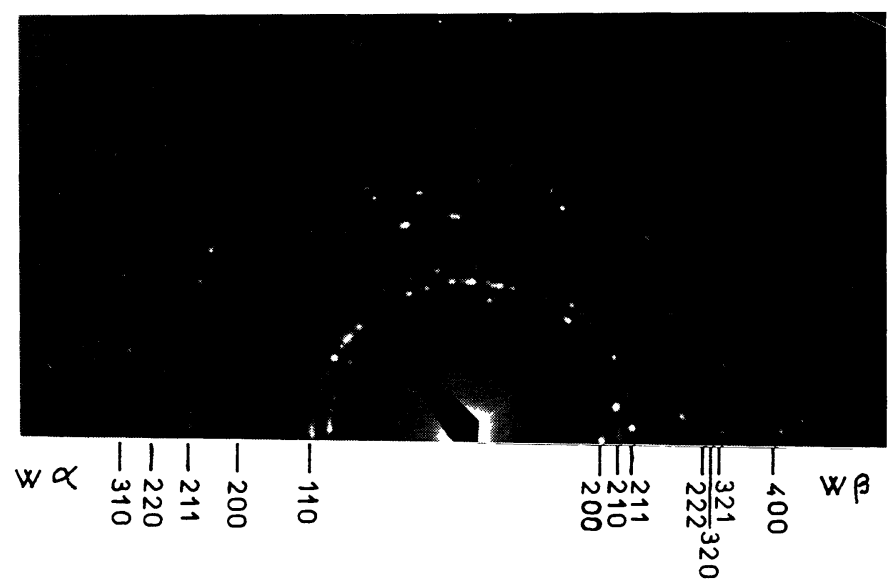

Fig. 12. - Selected area electron diffraction diagram corresponding to a tungsten film deposited with $-50 \mathrm{~V}$ bias voltage. The main reflections of the $\alpha$ and $\beta$ tungsten are observed.

\section{Conclusion.}

Three main properties have been studied : resistivity, stress and microstructure. Bias voltage and instantaneous temperature have a significant impact on the $\mathrm{W}$ characteristics :

- (i) films deposited at low power density $\left(1.7 \mathrm{~W} . \mathrm{cm}^{-2}\right)$ under zero bias are composed of only $\beta$-W phase whatever the thickness in the range from 50 to $500 \mathrm{~nm}$; no other phase is observed. The perfection of the texture is improved with the temperature. Low tensile stresses $(<500 \mathrm{MPa})$ but high resistivity $(0.8-2 \mu \Omega . \mathrm{m})$ are measured.

- (ii) with a low negative bias voltage, the $\beta$-W phase disappears for the benefit of a $\alpha$-W and $\beta$ $\mathrm{W}$ mixture. At high values $(-150 \mathrm{~V})$, only $\alpha-\mathrm{W}$ phase is detected. The increase of this deposition parameter corresponds to a reduction of the resistivity $(0.1 \mu \Omega$.m for $-150 \mathrm{~V})$ attributed to the formation of $\alpha$ phase and a change of stresses from tensile to highly compressive. The stress level can be reduced at almost 0 by adjustment of the polarisation. But the zero stress and the minimum resistivity are not reached for the same deposition conditions. Nevertheless, a compromise was found to induce both low resistivity and low stress. $-50 \mathrm{~V}$ seems to be the solution of this problem. For this particular bias value, the microstructure consists of a mixture of $\alpha-\mathrm{W}$ and $\beta$-W. Finally the paper presented here shows that $\mathrm{W}$ films deposited on $\mathrm{SiO}_{2}$ substrates and using rf magnetron sputtering can be used as a "glue layer".

\section{Acknowledgements.}

The authors would like to thank S. Lequien (LCR Thomson) for X-ray diffaction observations of numerous samples and D. Rouhaud for assistance with film deposition. This work was supported by the Centre National de la Recherche Scientifique (GDR No.86). 


\section{References}

[1] Petroff P., Sheng T.T., Sinha A.K., Roz Gonyi G.A., Alexander F.B., J. Appl. Phys. 44 (1973) 2545.

[2] Ruterana P., Chevalier J.P., Houdy P., J. Appl. Phys. 65 (1989) 3907.

[3] Hugon M.C., Varniere F., Agius B., Froment M., Arena C., Bessot J., Appl Surf Sci 38 (1989) 269.

[4] Collot P., Agius B., Estrache P., Hugon M.C., Froment M., Bessot J., Crassin Y., J. Vacuum Sci. Technol. A 6 (1989) 2319.

[5] Wagner R.S., Sinha A.K., Sheng T.T., Levinstein H.J. and AleXAnder F.B., J. Vac. Sci. Technol. $11(1974) 582$.

[6] Gasgnier M., Nevot L., Baillif P. and Bardolle J. Phys. Status. Solidi. 79 (1983) 531.

Cet article a été imprimé avec le Macro Package "Editions de Physique Avril 1990". 